Review Article

\title{
Characterization and Functions of Protease-Activated Receptor 2 in Obesity, Diabetes, and Metabolic Syndrome: A Systematic Review
}

\author{
Satomi Kagota, ${ }^{1}$ Kana Maruyama, ${ }^{1}$ and John J. McGuire ${ }^{2}$ \\ ${ }^{1}$ Department of Pharmacology, School of Pharmacy and Pharmaceutical Sciences, Mukogawa Women's University, \\ Nishinomiya, Hyogo 6638179, Japan \\ ${ }^{2}$ Cardiovascular Research Group, Division of BioMedical Sciences, Faculty of Medicine, Memorial University, St. John's, \\ Newfoundland and Labrador, Canada A1B 3V6
}

Correspondence should be addressed to John J. McGuire; mcguire@mun.ca

Received 20 October 2015; Accepted 26 January 2016

Academic Editor: Andrea Mencarelli

Copyright (C) 2016 Satomi Kagota et al. This is an open access article distributed under the Creative Commons Attribution License, which permits unrestricted use, distribution, and reproduction in any medium, provided the original work is properly cited.

\begin{abstract}
Proteinase-activated receptor 2 (PAR2) is a cell surface receptor activated by serine proteinases or specific synthetic compounds. Interest in PAR2 as a pharmaceutical target for various diseases is increasing. Here we asked two questions relevant to endothelial dysfunction and diabetes: How is PAR2 function affected in blood vessels? What role does PAR2 have in promoting obesity, diabetes, and/or metabolic syndrome, specifically via the endothelium and adipose tissues? We conducted a systematic review of the published literature in PubMed and Scopus (July 2015; search terms: par2, par-2, f2lr1, adipose, obesity, diabetes, and metabolic syndrome). Seven studies focused on PAR2 and vascular function. The obesity, diabetes, or metabolic syndrome animal models differed amongst studies, but each reported that PAR2-mediated vasodilator actions were preserved in the face of endothelial dysfunction. The remaining studies focused on nonvascular functions and provided evidence supporting the concept that PAR2 activation promoted obesity. Key studies showed that PAR2 activation regulated cellular metabolism, and PAR2 antagonists inhibited adipose gain and metabolic dysfunction in rats. We conclude that PAR2 antagonists for treatment of obesity indeed show early promise as a therapeutic strategy; however, endothelial-specific PAR2 functions, which may offset mechanisms that produce vascular dysfunction in diabetes, warrant additional study.
\end{abstract}

\section{Introduction}

Obesity, diabetes, and metabolic syndrome are risk factors for cardiovascular disease. Insulin resistance and high blood glucose levels can lead to endothelial dysfunction, a cardiovascular complication of these dysmetabolism states and a common pathology of cardiovascular disease [1]. Endothelial dysfunction impairs regulation of vascular smooth muscle tone and vasodilation, which reduces oxygen supply and inhibits the capacity of tissues and organs to meet changes in metabolic demand [2]. Improving cellular metabolism and preserving, restoring, and/or rescuing endothelial cellregulated vascular functions like vasodilation are desirable features for new therapeutics.

This study is a systematic review of the literature providing evidence that proteinase-activated receptor 2 (PAR2) is involved in obesity, diabetes, and metabolic syndrome. PAR2 is a cell surface receptor that is activated by endogenous serine proteinases or pharmacologically by synthetic ligands (Figure 1) [3, 4]. On the one hand, PAR2 activation could preserve blood flow associated with specific endothelial cell mechanisms; on the other hand, PAR2 activation could also stimulate inflammation pathways, which may impair cellular metabolism, produce insulin resistance, and promote obesity and diabetes [5]. Our objective for this review was to gain a better understanding about PAR2 effects-especially its activation versus inhibition-in studies of obesity, diabetes, and metabolic syndrome. Two specific questions were asked: How is PAR2 function affected in blood vessels? What role does PAR2 have in promoting obesity, diabetes, and/or metabolic syndrome, specifically via the endothelium and 


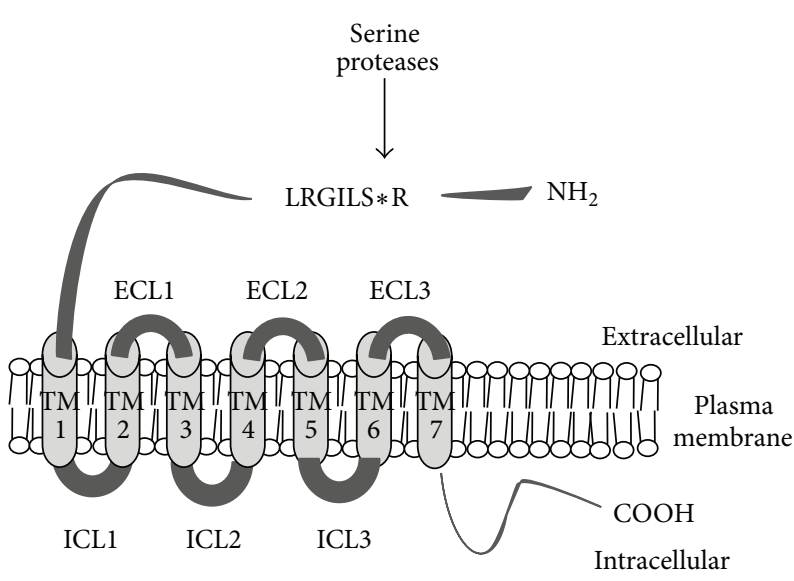

(a)

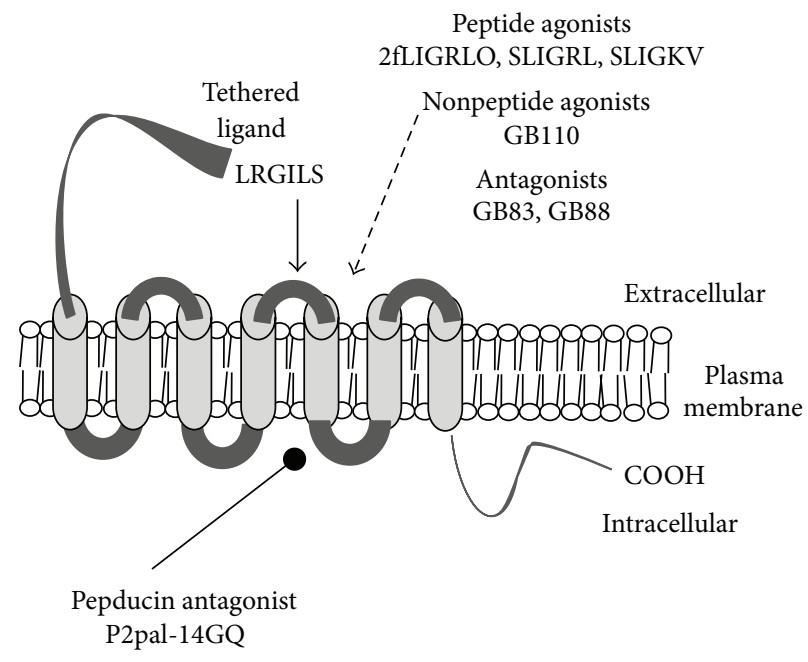

(b)

FIGURE 1: Activation of protease-activated receptor 2. (a) PAR2 is a seven-transmembrane domain cell surface receptor that can be activated by serine proteases which recognize a substrate sequence on the $\mathrm{N}$-terminus $\left(-\mathrm{NH}_{2}\right)$ located in the extracellular space. To highlight the unique mechanism of action a simplified cartoon shows the arrangement of the nonactivated PAR2 protein sequence (ribbon) in a cell plasma membrane. Asterisk indicates the site of proteolytic cleavage of mouse and rat PAR2 associated with serine proteases, including trypsin, human mast cell $\beta$-tryptase, matriptase, and several human kallikreins. (b) Following proteolytic cleavage, the newly revealed N-terminus (shown as LRGILS) acts as a tethered ligand that interacts (solid arrow) with the extracellular loop-2 (ECL-2) domain and induces the activated state of the receptor. Alternatively, receptor activating peptides (2fLIGRLO, SLIGRL, and SLIGKV), and nonpeptide agonists (GB110) can activate PAR2 without the participation of proteases (dashed arrow). Also, shown are the proposed sites of action of different classes of PAR2 antagonists, that is, GB83, GB88 (dashed arrow) and PAR2 pepducin P2pal-14GQ (oval arrow). Peptide sequences are identified by their amino acid sequences using the standard capitalized one-letter abbreviations. All PAR2 activating peptides were synthesized as amides. Sequence starting with $2 \mathrm{f}$ indicates $\mathrm{N}$-terminal modification with a 2-furoyl functional group. COOH: carboxy terminus; ECL: extracellular loops domains 1 to 3; ICL: intracellular loop domains 1 to 3; TM: transmembrane loop domains 1 to 7.

adipose tissues? This review identifies current trends and knowledge gaps about PAR2 actions in obesity, diabetes, and metabolic syndrome. Addressing these gaps may improve the strategies to address obesity and/or diabetes or raise important issues to be addressed as pharmaceutical development proceeds with PAR2-based drugs.

In the vasculature, PAR2, a seven-transmembrane classA GPCR [6], is constitutively expressed in endothelial cell [7] and inducible in endothelial cell and vascular smooth muscle cells $[8,9]$. The canonical description for the mechanism of PAR2 action is that specific PAR2-activating compounds and serine proteinases activate Gq-alpha, which via phospholipase $\mathrm{C}$ activity increases intracellular IP3 and activates IP3R and results in the release of internal stores $\mathrm{Ca}^{2+}$ as shown in [10]. PAR2 signal transduction mentioned above is recognized as being more complex (reviewed in [11]) than a single agonist-receptor pathway. Thus, PAR2 signalling by the internalized receptor [12], transactivation of other receptors [13], subcellular localized receptor distributions [14], tethered-ligand disarming [15], and agonist-biased signals [16] contribute to a complex system of PAR2 mediated cell responses.

Serine proteases like trypsin $[4,17]$ and human mast cell $\beta$-tryptase [18], matriptase [19], and several isoforms of human kallikreins [20] activate PAR2 by a mechanism involving a self-contained tethered ligand (Figure 1) [6], which is produced by proteolytic cleavage within a specific sequence of PAR2's amino terminus and binds to sites in its extracellular loop 2 domain [21]. Nonserine proteases, including elastase and cathepsin $\mathrm{S}$, have also been reported to recognize substrate sequences within the $\mathrm{N}$-terminus of PAR2 and thus produce alternate truncated extracellular $\mathrm{N}$ terminus $[15,22]$. Some of these truncations will effectively disarm the receptor by removing the region used for activation by other proteases and other truncations may induce an activation of PAR2 signal transduction [23].

A broad range of pharmacological tools (Figure 1) are available for examining PAR2 (reviewed in [24]), including PAR2-activating peptides [25-28], small molecule PAR2 agonists [29-32] and antagonists [33, 34], cell permeable pepducins [35], and anti-receptor antibodies [36]. PAR2activating peptides are short peptides synthesized to match the N-terminal amino acid sequence of the PAR2 tethered ligand revealed by trypsin and trypsin-like serine proteases [27]. For example, SLIGKV and SLIGRL match the Nterminus sequences of human and rodent (mouse and rat) PAR2, respectively [26]. Modifications (e.g., substitutions and additions) to the synthetic PAR2-activating peptides change the potency, increase in vitro resistance to peptidases, and provide sites to tag with labels for ligand-binding [37] and receptor visualization studies [38]. 2-Furoyl-LIGRLO (2fLIGRLO) is one example of a compound derived from the template SLIGRL and is the most potent PAR2 peptide agonist in use since its discovery [28]. GB110 is a nonpeptide 
compound with good potency and selectivity for activating PAR2 [29, 33]. Researchers examined the effect of changing the carboxy-terminus of GB110 to different spiropiperidines and as a result identified two compounds, GB83 and GB88, which are selective and potent inhibitors of PAR2-activation by either activating peptides or serine proteases [33]. This distinction was particularly notable because another PAR2 antagonist, ENMD-1068, inhibited only enzyme activation of PAR2 [39]. GB88 administered in vivo reduced inflammation in various models of inflammation [40, 41]. However, the more recent study provides evidence that GB88 is a selective antagonist of PAR2-mediated intracellular calciumrelease and a partial agonist of other PAR2-mediated signal transduction, for example, ERK phosphorylation [41]. A separate group of researchers has developed a different PAR2 antagonist, C391, which blocked multiple PAR2-mediated cell signaling pathways [34]. A different technology strategy for pharmacological inhibition of PAR2 is the development of pepducins, which are a class of lipid soluble peptide compounds that target the intracellular regions of GPCR [42]. PAR2 pepducins (e.g., P2pal-21F and P2pal-18S) are aminoterminus palmitoylated peptides that use the intracellular loop three of PAR2 as a template amino acid sequence [35]. P2pal-21F is a nonselective agonist of PAR2 and PAR1 whereas P2pal-14GQ is a selective antagonist of PAR2 [35]. P2pal-14GQ is the most potent of a series of PAR2 pepducins that inhibited PAR2-mediated cell signaling and was antiinflammatory in a PAR2-depenent inflammation model [35].

In endothelial cells, PAR2-mediated $\mathrm{Ca}^{2+}$-release activates nitric oxide synthase [25] and $\mathrm{Ca}^{2+}$-activated potassium channels [43], relaxes vascular smooth muscle, dilates arteries, increases tissue perfusion, and lowers blood pressures [44]. Yet in contrast to these potentially beneficial effects on cardiovascular function, studies have provided evidence demonstrating PAR2 activation can promote inflammation responses, for example, by inducing cytokine release [19] and adhesion molecule expression [45]. However, PAR2 mediated pathophysiology is not associated with any singular serine proteinase, which would appear to leave a wide scope of potential roles for the receptor and potential mediators in obesity, diabetes, and metabolic syndrome.

\section{Methods}

Studies were selected for review by searching PubMed and Scopus databases (last search updated July 2015). In one arm of the search, the terms were ((par2 or par-2 or f2rl1) endothelium) and (diabetes or obesity or adipose or metabolic syndrome). PAR2 and PAR-2 have been more commonly used than f2rll (factor 2 receptor like 1), which is the most recent name assigned to the gene encoding PAR2 and highlights the gene homology shared with factor 2 receptor (f2rl, PAR1, or the thrombin receptor). In the other arm of the search, the keywords were ((par2 or par-2 or f2rl1) and (diabetes or obesity or adipose or metabolic syndrome) not endothelium. These searches produced 10 and 35 results. Three additional studies were identified by citations in the search articles. Each study was abstracted and reviewed for relevance and, subsequently, content. Tables 1 and 2 list all the included studies from first [46-48, 50-53] and second arm [54-60, 62-67], respectively. Reviews, editorial articles, and papers that did not pertain to protease-activated receptors or deemed to have peripheral or limited direct relevance to diabetes, obesity, or metabolic syndrome were excluded from further study.

\section{Results}

3.1. PAR2 Endothelial Cell Mechanisms in Obesity, Diabetes, and Metabolic Syndrome. PAR2 expression on endothelial cell [7] and adipocytes [48] is constitutive. Inflammatory mediators [68] and dietary fatty acids [63] can induce PAR2 expression in endothelial cells and adipocytes, respectively. From separate studies, it is known that PAR2 activation by specific activating compounds and enzymes cause endothelial cell-mediated vascular smooth muscle relaxation, dilate blood vessels, increase blood flow, and lower blood pressures [44].

All studies listed in Table 1, except for a single study [48] reported PAR2-mediated relaxations of blood vessels that were preserved or increased in animals with obesity [53], diabetes (type 1 [46] or type $2[47,50,51]$ ), or metabolic syndrome [52]. These results on their own suggest that PAR2 activation may preserve local or regional blood flows in the face of endothelial dysfunction. The shared result is interesting because several different rodent models associating endothelial dysfunction with metabolic status were utilized. In these studies, PAR2 was compared with muscarinic [ 46,47 , 50-52] or bradykinin [53] receptor mechanisms of vasodilation; both of which were impaired, consistent with their use as internal references for endothelial dysfunction in these models. Unfortunately, Li et al. [48] did not provide data to allow comparison of PAR2 endothelial cell-mediated vasodilation between healthy (C57B6) and noninsulin dependent diabetes models (type 2; TallyHo mice). The cellular (endothelial cell versus vascular smooth muscle cell) and subcellular mechanisms explaining the PAR2 mediated relaxations vary-for example, nitric oxide $[47,50,52]$, cyclooxygenases $[46,50]$ or $\mathrm{Ca}^{2+}$-activated $\mathrm{K}^{+}$channels $[51,53]$ have been inferred as primary mediators-between studies. Differences in the choices of experimental models and types of blood vessel preparations (aorta [46, 47], coronary arterioles [50], small mesenteric artery branches [51,52], middle cerebral artery [53], and superior-mesenteric artery [52]) may contribute to some of the mechanistic variations between each study.

In the studies listed in Table 1, all of the experimental group animals displayed elevated blood glucose $[47,48,50$, $51,53]$ and or urine glucose $[46,51,52]$ levels, consistent with the premise of metabolic dysregulation. In two of the four studies with type 2 diabetes models, the diabetic animals $(\mathrm{db} / \mathrm{db}$ mice) were obese and weighed more than lean controls [50,51]. Glucose intolerance, high levels of serum insulin and blood lipids, larger body masses, and high systolic arterial blood pressures were confirmed in the rat model of metabolic syndrome [52]. Underlying causes of hyperglycemia, insulin resistance, and/or obesity included genetic propensities for type 1 [46] and type 2 diabetes [47, 48, 50-52] and a high-fat high-carbohydrate diet [53]. As shown 


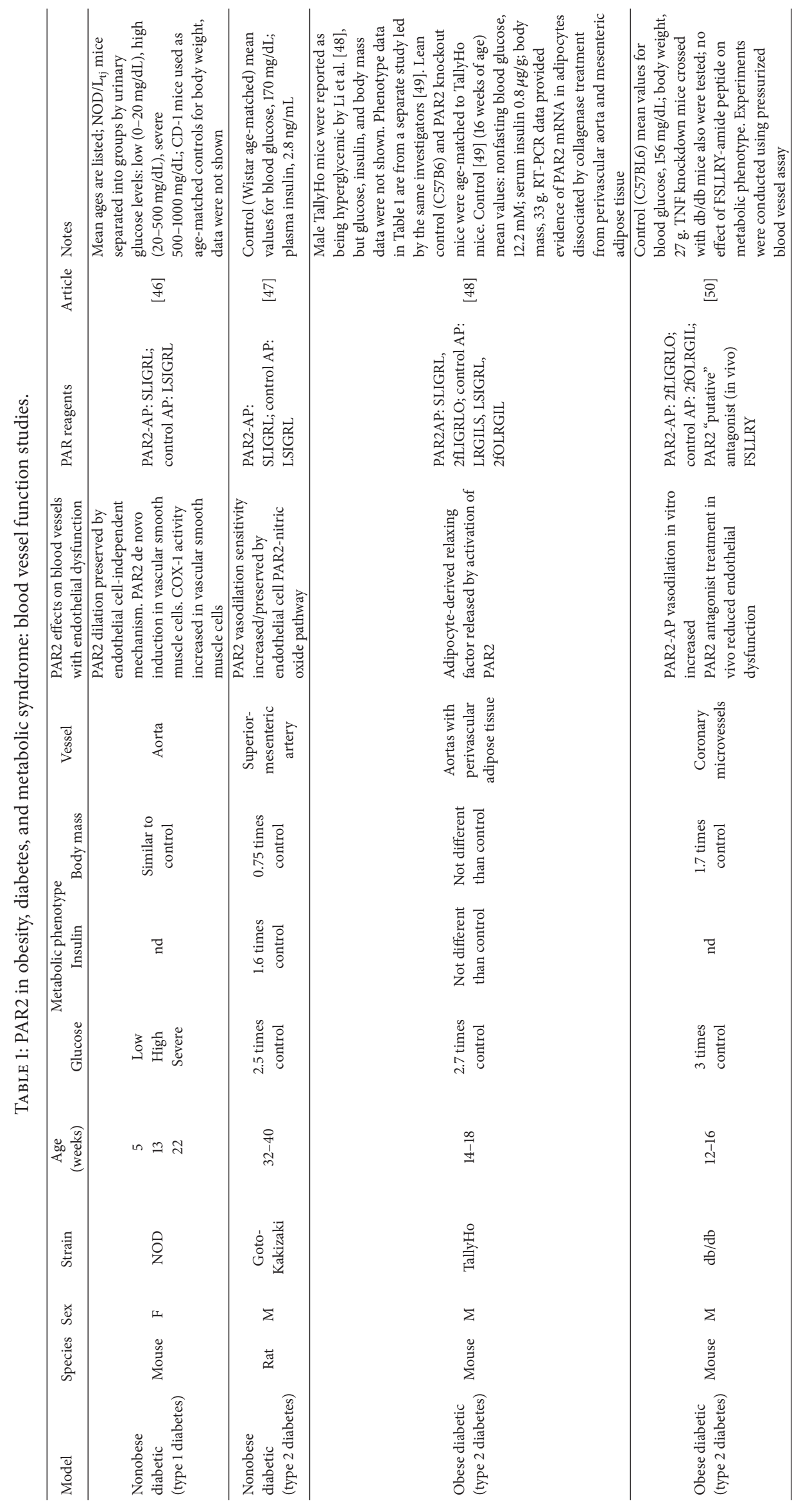




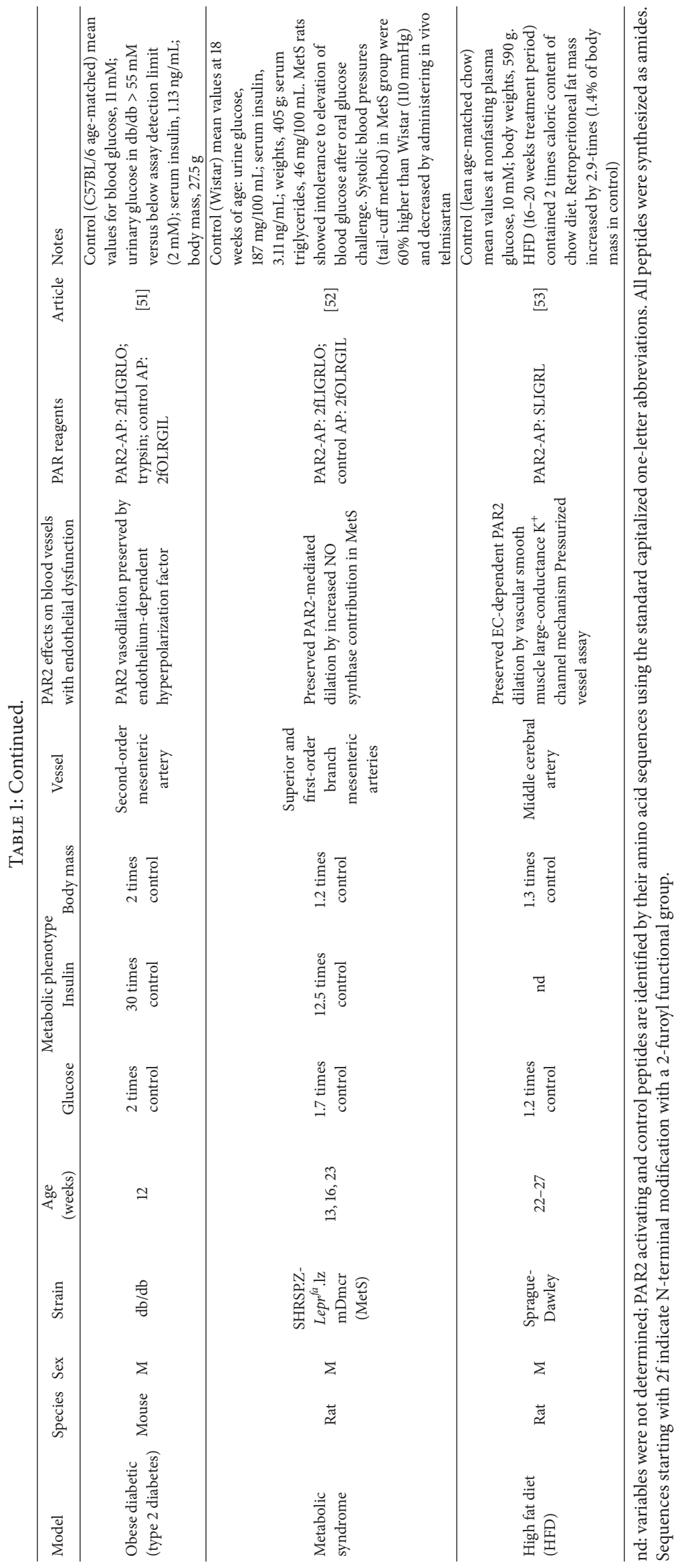


in Table 1, the metabolic phenotypes of the experimental groups were broadly categorized: nonobese diabetic [46, 47], obese diabetic [48,50,51], diet-induced obesity [53], and metabolic syndrome (high blood pressure [52]). One study [52] examined the reversal of hypertension and elements of endothelial dysfunction on PAR2 and blood vessel function after treatment of animals with telmisartan, an angiotensinII type 1 receptor antagonist. Two studies by independent research groups $[50,51]$ examined obese diabetic $\mathrm{db} / \mathrm{db}$ mice. However, each group looked at outcomes in different vasculatures. Treatment in vivo with a putative PAR2 antagonist peptide reportedly reversed endothelial dysfunction in the coronary vasculature of the $\mathrm{db} / \mathrm{db}$ [50]. Each of the other studies in Table 1 used a different experimental model; some models produced similar metabolic phenotypes despite being based in different species or strains of rodents.

Only two studies reported using nonobese diabetic animals to study PAR2 in the vasculature. These studies found the same trend for sustained PAR2 vasodilation [46, 47]. In nonobese type 1 diabetic female mice [46], PAR2 mediated dilations of aortas were preserved by an increased release of COX-2 dependent prostaglandins. By comparison with another nonobese rodent model of type 2 diabetes, male Goto-Kakizaki rats [47], a cyclooxygenase inhibitor had no effect on PAR2 mediated relaxation of the superior mesenteric artery; the proposed explanation was an increase in PAR2 expression that compensated for decreased vasodilator mediators. No direct comparisons between obese and nonobese diabetic models have been reported.

Age-dependent outcomes were assessed in a few studies as a part of the model employed $[46,52,53]$. In such cases, time-course changes in the sensitivity to PAR2 appeared to increase with the progression of the metabolic disease [46, 52, 53]. Within the studies listed in Table 1 , the effects of sex on PAR2-dependent responses in blood vessels have not been examined; most of the studies exclusively used male animals [47, 51-53]. Indeed the few studies that included female subjects did not account for sex in reporting or analyzing data $[46,48,50]$. All studies in Table 1 were conducted in rodents. Mouse strains included CD-1, FVB/N, and NOD/Ltj [46]; TallyHo [48]; C57BL6 [48, 51]; rat strains included Wistar [47, 52] and Sprague-Dawley [53]. Organ bath [47, 52] and small wire-myograph $[46,48,51]$ bioassay methods outnumber the isolated perfused vessel preparations $[50,53]$ for assessing endothelial function in blood vessels. Endothelial function was measured in all cases by the reversal of blood vessel constriction, using pretreatment with agonist that varied in each preparation. PAR2-activting peptides, SLIGRL [46$48,53]$ or 2fLIGRLO [48, 50-52], were used as agonists for PAR2 activation. Only one study [51] also used trypsin, a serine protease that activates PAR2 at low concentrations and PAR1 at high concentrations. Similarly only Li et al. [48] examined blood vessel function with PAR2 in the presence of perivascular adipose tissue, identifying adipose-derived relaxing factors elicited by PAR2 agonist (SLIGRL). Interestingly, the PAR2-inactive peptides (LRGILS and 2fOLRGIL) caused a PAR2-indepdent release of a pharmacologically distinct adipose-derived relaxing factor [48].
In a couple of studies [46, 50], immunohistochemistry data provided preliminary qualitative evidence corroborating the increased expression of PAR2 within the selected blood vessel. Quantifying PAR2 expression in tissues has been problematic because the same tools (antibodies) used in Western blot methods demonstrated evidence of off-target signals [51, 69] and, thus, challenge the validity of concluding that PAR2 expression increased [46, 47, 50]. Quantitative real-time PCR has been used to assess par2 gene expression [51, 52] and is indirect evidence of protein expression. In general, evidence of the subcellular distribution of PAR2 within endothelial cells of the vessels is lacking in these studies, but based on functional studies (i.e., removing the endothelium and using genetic PAR2 knockouts) the expression of PAR2 in endothelial cells is critical to the blood vessel function in all except two studies [46, 48]. However, between these latter studies, only Roviezzo et al. [46] compared endothelial cellmediated vasodilation by PAR2 between the healthy and disease states. Previously, the other investigators provided evidence of endothelial dysfunction in aortas of TallyHo mice, based on experiments using only acetylcholine as the primary agonist [49].

Metabolic syndrome was examined in a single experimental model [52] that combined high arterial blood pressure with the altered metabolic parameters. This SHRSP.ZF rat model points to sustained nitric oxide-mediate mechanisms underlying PAR2 activation of arteries [52]. Interestingly, angiotensin-II receptor 1-antagonist treatment in this same model did not affect the sustained PAR2 mechanism and restored function to other endothelial cell agonists by reestablishing nitric oxide-mediated vasodilation [52]. A number of factors in this model, including age, sex, and disease progression, warrant further study to delineate the regulation of PAR2 under the conditions of metabolic syndrome. This model [52] in particular may be useful for following up the cardiometabolic consequences of PAR2 function inferred by the studies in Table 2 .

\subsection{PAR2 Signalling Mechanisms in Obesity, Diabetes, and Metabolic Syndrome}

3.2.1. Experimental Models. As summarized in Table 2, researchers have applied separately in vitro and in vivo methodologies for examining the role of PAR2 signalling in obesity and diabetes, outside of the context of endothelium function [54-60, 62-67]. Overall, there is a trend of finding increased PAR2 expression in tissues from obese humans [63] and rodents, which included obesity with or without diabetes. Causes of obesity and diabetes in these models included genetic mutations $[56,58,59]$, high fat diets [57, 67], or $\mathrm{T}$ cell mediated pancreatic islet destruction [55]. In some but not all studies, the increases in mRNA expression or immunospecific staining of tissues were corroborated by functional responses to agonists of PAR2 [54-56, 60, 63]. PAR2-activating peptides (2fLIGRLO [56, 63], SLIGRL [54, $55,63]$, and SLIGKV $[64,65]$ ) were more commonly used as agonists, with fewer studies having used trypsin activation of PAR2 [54, 60, 64]. Interesting trends in the research themes include studies of transactivation of PAR2 by cell specific 


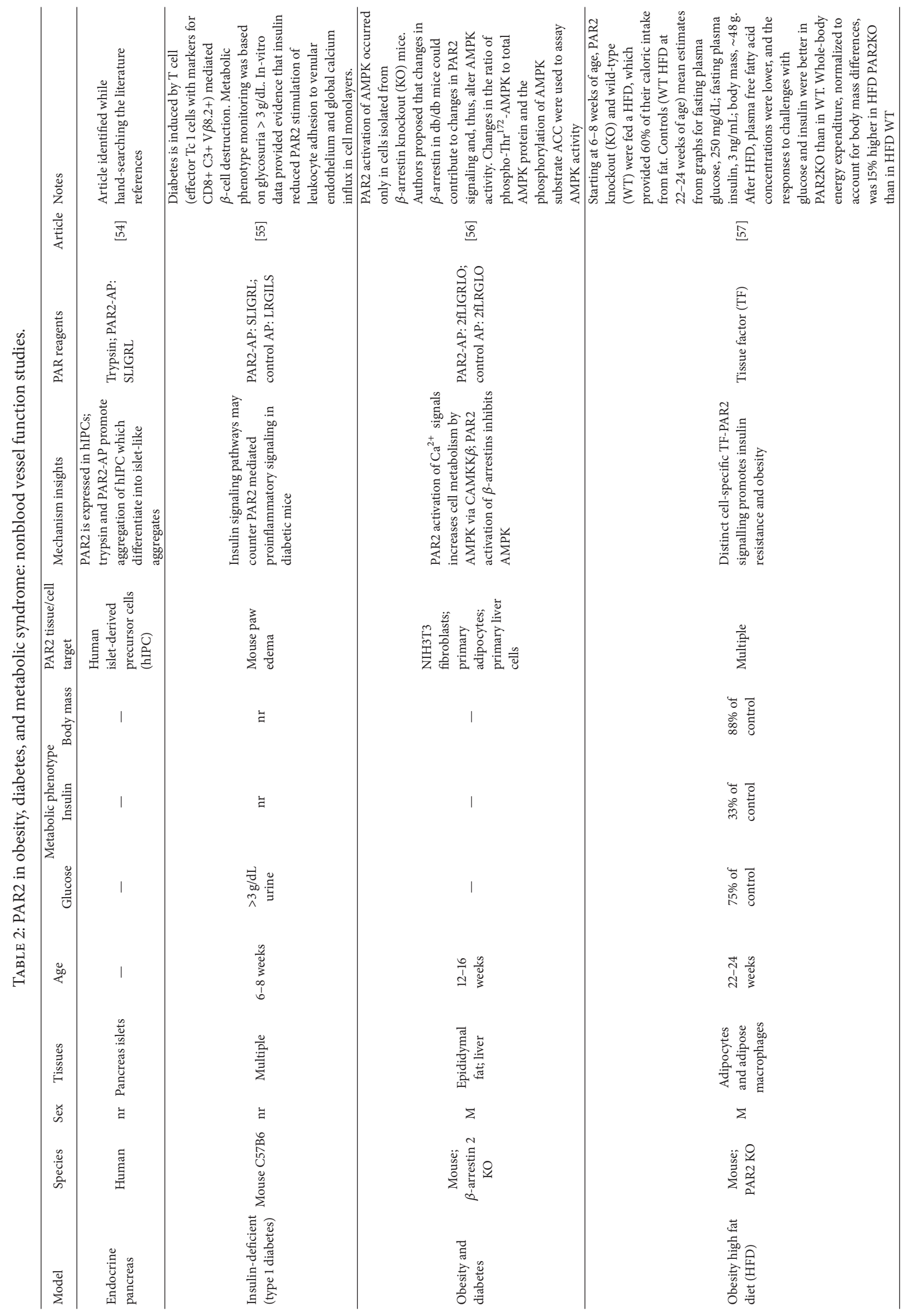




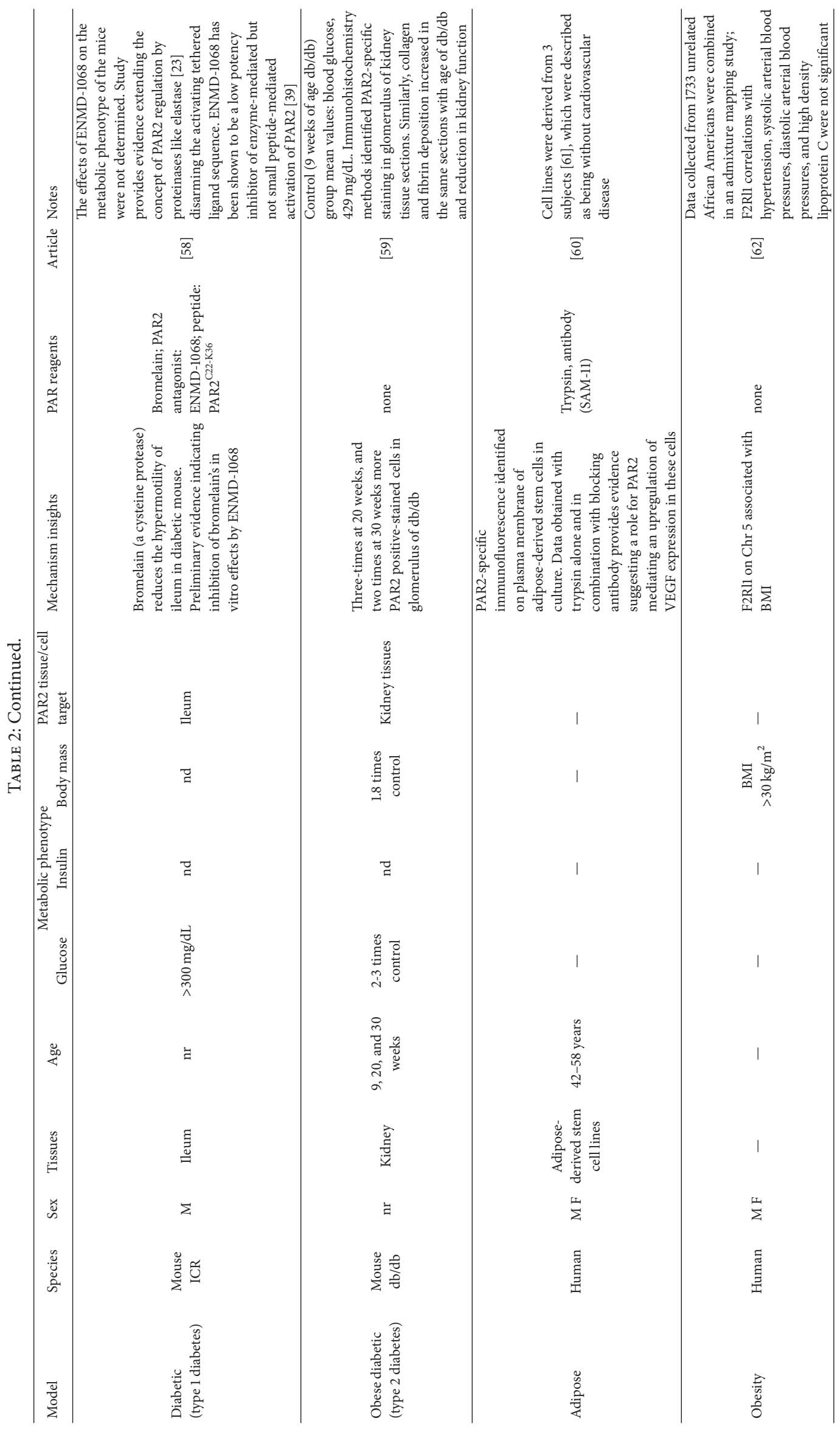




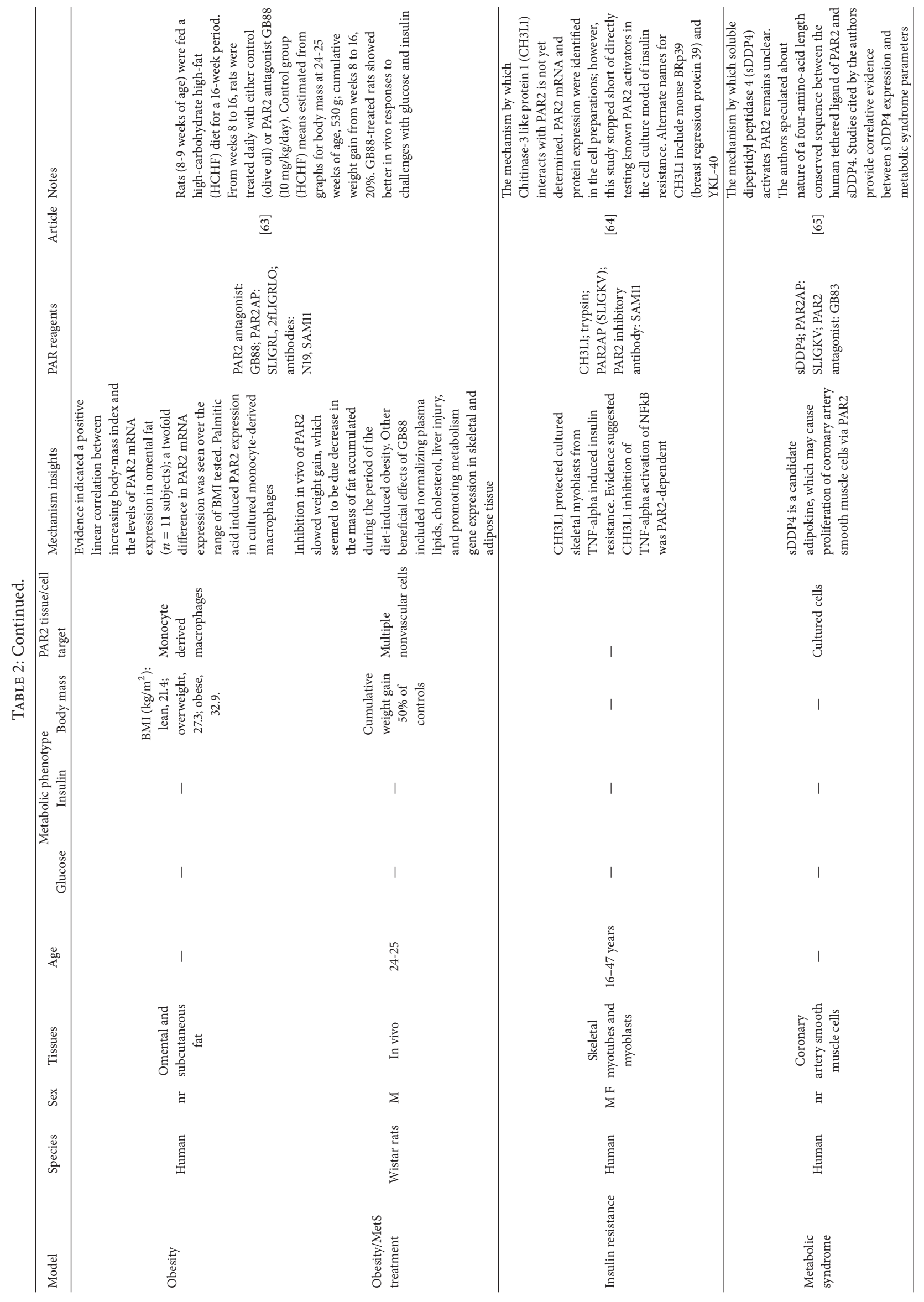




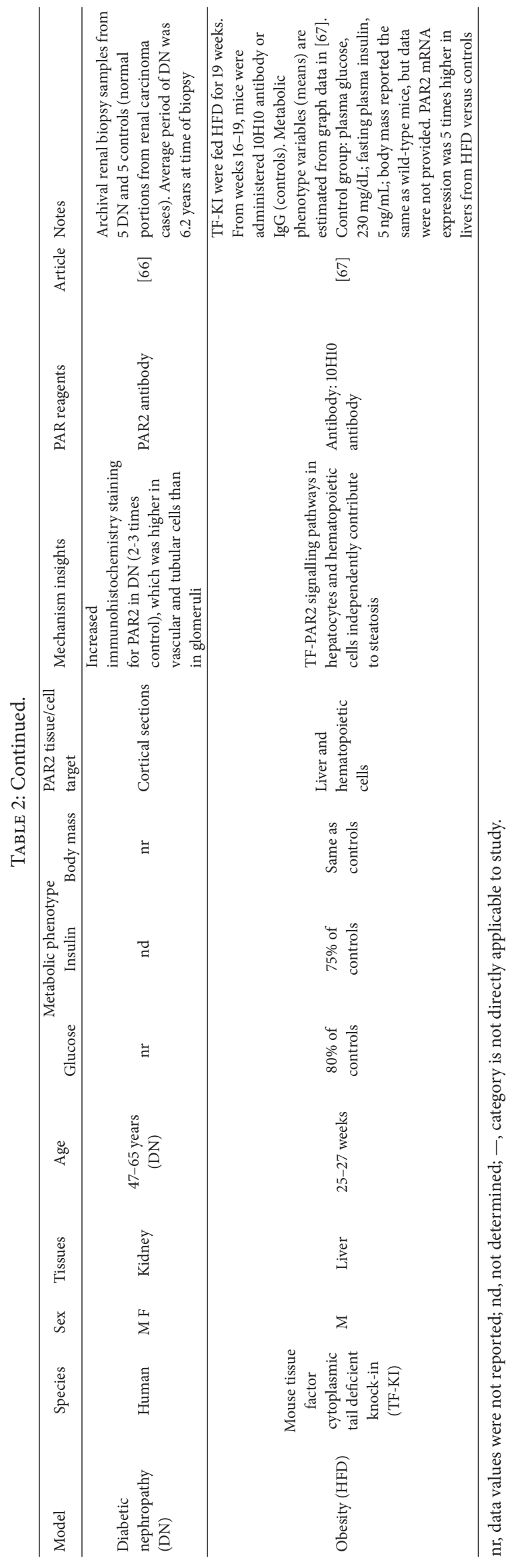


receptors, for example, the cytoplasmic tail of tissue factor $[57,67]$ or epidermal growth factor receptor, and the regulation of metabolic pathways by PAR2, for example, AMPactivated kinase [56, 57, 67]. Such research seeks answers to address the question of how PAR2 is linked to regulation of cell metabolism and proposes novel interactions between metabolism and the immune system.

There is an increasing trend in the field of PAR research towards identifying novel activation pathways by endogenous proteases or nonserine proteases [58, 64, 65]. Studies listed in Table 2 have provided relatively weak evidence for any relationship between a specific protease $[58,64,65]$ as being an endogenous mediator of PAR2's role in diabetes and obesity. As we found with the studies of PAR2 with the vasculature, the studies [54-60, 62-67] listed in Table 2 have not systematically investigated age- or sex-related differences.

3.2.2. Signalling Pathways Differences/Heterogeneity. As shown by examples cited in this review, PAR2 intracellular signalling pathways vary by cell type and experimental conditions. Indeed the selectivity of activators for PAR2 $\mathrm{Ca}^{2+}$-dependent versus $\mathrm{Ca}^{2+}$-independent signaling has been proposed as an explanation differentiating actions of PAR2 by different enzyme agonists [70]. Recent studies indicate distinct roles for regulation of gene expression by PAR2 based on whether it is localized at the plasma membrane versus the cell nucleus [14, 71]. Thus, recognition of PAR2 agonist-biased signalling is warranted for future studies that examine this receptor in disease models and consider the therapeutic potential of various PAR2 modulating compounds.

Blocking PAR2 signalling with small molecule antagonists and antibodies has been tested and resulted in reducing or normalizing adiposity and some metabolic parameters in the obesity models $[57,63,67]$. In one case using the dietinduced obesity/metabolic syndrome rat model [63], supplementary data provided evidence that GB88, a biased PAR2 antagonist, treatment blunted the effect of HCHF-feeding on several indices of cardiac function and the interstitial collagen content in the left ventricular myocardium; however, cardiac output was not different between controls and treatments. Systolic blood pressures of HCHF + GB88 group were less $(\sim 10 \%)$ than HCHF alone. Further examination of GB88 action in vivo when placed in combination with selective PAR2 antagonists, for examples, pepducin P2pal-14GQ [35], could provide further insight into cellular mechanisms. Studies in par2 knockout mice indicated eliminating par 2 function had a modest effect on raising systolic blood pressures [72] and, thus, may counter the benefits of lowering the rate of adiposity gain under a high fat diet. Integrating the models of PAR2 function in the vasculature with its concomitant actions elsewhere, which promote obesity, is a logical step toward a better understanding of the balance of PAR2 therapeutics for metabolic dysfunction and cardiovascular risk.

\section{Discussion}

We conducted this review in order to evaluate the role of PAR2 in obesity, diabetes, and metabolic syndrome as well as identifying trends in this research field. We found that PAR2 was linked to obesity, diabetes, and metabolic syndrome by two separate, but not mutually exclusive research themes, which we identified by their focus on PAR2-mediated endothelial cell functions or not. This division of the literature along two themes is relevant because endothelial dysfunction is a characteristic factor of cardiovascular complications in diabetes. Strategies for pharmaceutical interventions targeting PAR2 should account for both vascular function and metabolism effects in diabetes.

The first theme we identified in the literature centers on the role of PAR2 on endothelial cells and their function or dysfunction in regulation of circulatory control in metabolic syndrome obesity and or diabetes [46-48, 50-53]. In these studies, a case is made for the presence of sustained PAR2 mediated vasodilation in the diabetic, obese, or metabolic syndrome state that is consistent with the broader literature about preserved PAR2 functions on arterial vasculature, for example, in other models of circulatory diseases, conditions (ischemia), and injury [45, 51, 73-79]. Under this theme, studies focused on the functional local consequences of PAR2 activation on blood vessels and strategies have applied various rodent models [46-48, 50-53]. Tissue responses to PAR2 activation are assayed by the endothelium dependent or independent mechanism in the functional responses of blood vessels $[46-48,50-53]$. These studies vary by the age of animals, sex, species, and the vessel types (Table 1). In some cases the mechanisms are explored and the mediators of the pathways include nitric oxide, cyclooxygenases, and endothelium-dependent hyperpolarization [46-48, 50-53]. A development in the literature is a role proposed for PAR2 as a regulator of vascular tone via perivascular adipose tissue, specifically via adipocytes [48]. Others reported finding PAR2 expression in a nonadipocyte fraction of PVAT, which included infiltrating immune cells [63]. PAR2 differentiates from other GPCR by its activation of paracrine factors from perivascular adipose tissue that affect function of the blood vessels [48]. Such studies bridge a blood vessel-centered focus on circulatory function with evidence that PAR2 plays a role in inflammation pathways that link to metabolic dysfunction, outlined in the next section.

In the second theme, researchers have focused on models residing primarily outside of the endothelial cell domain [54-60, 62-67]. These studies have provided insight into detailed intracellular signalling mechanisms that build a case for PAR2 promotion of obesity. A developing trend in this theme is a divergence on the focus of PAR2 regulation mediated solely by pairing of GPCR with an agonist; rather studies present PAR2 as a coreceptor associated with the complex signaling by other receptors, for example, by the cytoplasmic domain of tissue factor [57, 67]. Along a similar line, investigators are examining PAR2 modulation of cell functions mediated via $\beta$-arrestin dependent mechanisms [56]. Converging evidence points to a common pathway of 
AMPK regulation by PAR2 that can be modulated by $\beta 2$ arrestin expression [56, 57, 67]. Demonstrating PAR2 is a modulator AMPK, a key regulator of cell metabolism, is a significant advancement in understanding its effects on energy regulation in the whole organism and supports the notion of interventions based on PAR2 [57, 63, 67]. Strategies have used a mix of methods, ranging from in vitro cell culture studies, including human pancreas islet-derived precursor cells [54] and adipocyte-derived stem cell lines [60, 61] to gene transcription association studies in humans [62]. No evidence has been provided to indicate that regulation of endothelial cell-specific expression or activity contributes directly to the pathology of obesity, diabetes, or metabolic syndrome.

In regards to obesity, diabetes, and metabolic syndrome, there has been speculation that dipeptidyl peptidase-4 (DDP4) [65] and chitinase-3 like protein 1 (CH3L1) [64] activate PAR2. However, weaknesses identified in Table 2 raise serious doubts about either of these proteins modulating specifically PAR2. More broadly the literature supports the notion that activation of PAR2 is not mediated by a single proteinase but is dependent on the protease network of local environments. It is unclear how exposure to proteases from food plants [58] fits into PAR2 regulation of metabolism or cardiovascular function. In theory, specific proteases could mediate different functions based on the tissue examined or its health state. In separate studies, some kallikreins were shown to activate PAR2 [80] and the kallikrein-kinin system is associated with the pathophysiology of diabetes, mostly by mechanisms involving bradykinin (reviewed in [81]). Cultured aortic vascular smooth muscle cells, but not endothelial cells, have been shown to activate plasma prekallikrein and stimulate PAR2 and epidermal growth factor receptor transactivation [82]. There is a current gap in direct evidence linking PAR2 to the kallikrein-kinin system in the pathophysiology of diabetes. However, the expression of PAR2 in tissues and organs (kidneys) susceptible to damage in diabetic humans [66] strengthens the rationale for further studies.

There have been few investigations conducted in humans that have found a relationship between PAR2 and obesity. A screening of thousands of single nucleotide polymorphisms in African Americans found a positive correlation between body mass index (BMI) and a PAR2 polymorphism [62]. In a separate small study, PAR2 mRNA expression in adipocyte tissues correlated with increasing the BMI of volunteer people [63]. Replication of these findings in other populations and identifying mechanisms underlying the single nucleotide polymorphism and activating agents would provide better understanding of scope of the impact on obesity and the significance if any for development of therapeutics targeting PAR2.

PAR2 is novel with regards to its response to vascular disease and is a pharmaceutical drug target. Vascular dysregulation is a common consequence of metabolic diseases, and new treatments are a priority for development. However, our understandings about PAR2 mechanisms in diabetes, obesity, and metabolic syndrome are based on preclinical laboratory models, which have included both type 1 and type 2 diabetic models. A point of controversy is whether PAR2 activation promotes obesity and, thus, further dysmetabolism in humans, because its expression correlated with BMI and at least in animal models, blocking PAR2 activity reduced adiposity and weight gain $[57,63]$. Investigations conducted in humans indicate that PAR2-activating peptides increase forearm blood flow by arterial and venous dilation and were well-tolerated by volunteers $[83,84]$. The discovery and development of new molecules to target PAR2 have been accelerating [24]. As newer agonist and antagonists of PAR2 $[31,34,85]$ become available to researchers, the clinical potential of such compounds will become more clear.

In preparation of this review, we strived to comment on all published peer-reviewed articles relating to PAR2 in obesity, diabetes, and metabolic syndrome. The authors acknowledge that these metabolic conditions and their complications are complex and involve many physiological systems. By focusing on the direct vascular actions of PAR2 and the implications for cardiovascular complications, we have not commented on the potential contributions of PAR2 to other related complications through other mechanisms and systems, for example, neuropathy and pain [86], itch [87], and dermatitis [88]. This review is intended to provide interested researchers with a summary of the models and experimental approaches. In an attempt to summarize diverse studies, some details that make each piece of work unique have been omitted. However, there are editorials and reviews focused on specific articles cited in the review, for example, [5, 89], which can offer interested readers alternative insights.

\section{Conclusions}

PAR2 activation can produce endothelial cell specific regulation of vascular function in the face of obesity, diabetes, and metabolic syndrome. There is yet no evidence directly linking endothelial cell-specific PAR2 to obesity, diabetes, or metabolic syndrome. However, PAR2 expression is observed within other target tissues that could regulate vascular function, for example, perivascular adipose tissue. In general the role of PAR2 in producing obesity, diabetes, and metabolic syndrome has been investigated entirely independent of the function of the vascular system and supports the development of pharmaceutical antagonists of PAR2. However, further research is needed to investigate the mechanisms underlying PAR2 function in the vasculature and interaction with pathophysiology in metabolic diseases, especially the role of endothelial PAR2, which may be able to rescue vascular health.

\section{Abbreviations}

BMI: Body mass index

CH3L1: Chitinase-3 like protein 1

DPP-4: Dipeptidyl peptidase-4

GPCR: Heteromeric G protein-coupled receptors

HCHF: High-carbohydrate high-fat

PAR2: Proteinase-activated receptor 2; protease-activated receptor 2; factor 2-receptor like 1; GPCR 11. 


\section{Conflict of Interests}

The authors declare that they have no competing interests.

\section{Authors' Contribution}

John J. McGuire and Satomi Kagota conceived the review, its design, and its coordination. All authors participated in the review of the scientific literature, contributed to the drafting and revision of the paper, and have read and approved the final paper.

\section{Acknowledgments}

The authors have received funding from the Canadian Institutes of Health Research (to John J. McGuire, ROP-88065 and RNL-120409); Research and Development Corporation Newfoundland (to John J. McGuire, 0708-022 and 5404.1146.106); Canada Foundation for Innovation (to John J. McGuire); the MEXT KAKENHI (to Satomi Kagota, no. 23590315). Funding agencies played no role in the decision to publish or make this submission.

\section{References}

[1] P. Dandona, A. Aljada, A. Chaudhuri, P. Mohanty, and R. Garg, "Metabolic syndrome: a comprehensive perspective based on interactions between obesity, diabetes, and inflammation," Circulation, vol. 111, no. 11, pp. 1448-1454, 2005.

[2] P. M. Vanhoutte, "Endothelial dysfunction in hypertension," Journal of Hypertension, Supplement, vol. 14, no. 5, pp. S83-S93, 1996.

[3] S. Nystedt, K. Emilsson, A.-K. Larsson, B. Strombeck, and J. Sundelin, "Molecular cloning and functional expression of the gene encoding the human proteinase-activated receptor 2," European Journal of Biochemistry, vol. 232, no. 1, pp. 84-89, 1995.

[4] S. Nystedt, A.-K. Larsson, H. Åberg, and J. Sundelin, "The mouse proteinase-activated receptor-2 cDNA and gene. Molecular cloning and functional expression," The Journal of Biological Chemistry, vol. 270, no. 11, pp. 5950-5955, 1995.

[5] F. Samad and W. Ruf, "Inflammation, obesity, and thrombosis," Blood, vol. 122, no. 20, pp. 3415-3422, 2013.

[6] M. D. Hollenberg and J. Trejo, Proteinase-Activated Receptors: PAR2, IUPHAR/BPS Guide to Pharmacology, 2015.

[7] M. Saifeddine, B. Al Ani, C.-H. Cheng, L. Wang, and M. D. Hollenberg, "Rat proteinase-activated receptor-2 (PAR-2): cDNA sequence and activity of receptor-derived peptides in gastric and vascular tissue," British Journal of Pharmacology, vol. 118, no. 3, pp. 521-530, 1996.

[8] F. Syeda, J. Grosjean, R. A. Houliston et al., "Cyclooxygenase-2 induction and prostacyclin release by protease-activated receptors in endothelial cells require cooperation between mitogenactivated protein kinase and NF- $\kappa \mathrm{B}$ pathways," The Journal of Biological Chemistry, vol. 281, no. 17, pp. 11792-11804, 2006.

[9] F. Bono, I. Lamarche, and J. M. Herbert, "Induction of vascular smooth muscle cell growth by selective activation of the proteinase activated receptor-2 (PAR-2)," Biochemical and Biophysical Research Communications, vol. 241, no. 3, pp. 762764, 1997.
[10] J. C. Hennessey, B. D. Stuyvers, and J. J. McGuire, "Small caliber arterial endothelial cells calcium signals elicited by PAR2 are preserved from endothelial dysfunction," Pharmacology Research \& Perspectives, vol. 3, no. 2, Article ID e00112, 2015.

[11] R. Ramachandran, F. Noorbakhsh, K. Defea, and M. D. Hollenberg, "Targeting proteinase-activated receptors: therapeutic potential and challenges," Nature Reviews Drug Discovery, vol. 11, no. 1, pp. 69-86, 2012.

[12] K. A. DeFea, J. Zalevsky, M. S. Thoma, O. Dery, R. D. Mullins, and N. W. Bunnett, " $\beta$-Arrestin-dependent endocytosis of proteinase-activated receptor 2 is required for intracellular targeting of activated ERK1/2," Journal of Cell Biology, vol. 148, no. 6, pp. 1267-1281, 2000.

[13] M. Saifeddine, M. El-Daly, K. Mihara et al., "GPCR-mediated EGF receptor transactivation regulates TRPV4 action in the vasculature," British Journal of Pharmacology, vol. 172, no. 10, pp. 2493-2506, 2015.

[14] J.-S. Joyal, S. Nim, T. Zhu et al., "Subcellular localization of coagulation factor II receptor-like 1 in neurons governs angiogenesis," Nature Medicine, vol. 20, no. 10, pp. 1165-1173, 2014.

[15] K. Mihara, R. Ramachandran, B. Renaux, M. Saifeddine, and M. D. Hollenberg, "Neutrophil elastase and proteinase-3 trigger G protein-biased signaling through proteinase-activated receptor1 (PAR1)," The Journal of Biological Chemistry, vol. 288, no. 46, pp. 32979-32990, 2013.

[16] M. D. Hollenberg, K. Mihara, D. Polley et al., "Biased signalling and proteinase-activated receptors (PARs): targeting inflammatory disease," British Journal of Pharmacology, vol. 171, no. 5, pp. 1180-1194, 2014.

[17] M. T. Fox, P. Harriott, B. Walker, and S. R. Stone, "Identification of potential activators of proteinase-activated receptor-2," FEBS Letters, vol. 417, no. 3, pp. 267-269, 1997.

[18] M. Molino, E. S. Barnathan, R. Numerof et al., "Interactions of mast cell tryptase with thrombin receptors and PAR-2," The Journal of Biological Chemistry, vol. 272, no. 7, pp. 4043-4049, 1997.

[19] I. Seitz, S. Hess, H. Schulz et al., "Membrane-type serine protease-1/matriptase induces interleukin- 6 and -8 in endothelial cells by activation of protease-activated receptor-2: potential implications in atherosclerosis," Arteriosclerosis, Thrombosis, and Vascular Biology, vol. 27, no. 4, pp. 769-775, 2007.

[20] R. Ramachandran, A. Eissa, K. Mihara et al., "Proteinaseactivated receptors (PARs): differential signalling by kallikreinrelated peptidases KLK8 and KLK14," Biological Chemistry, vol. 393 , no. 5, pp. 421-427, 2012.

[21] D. J. Lerner, M. Chen, T. Tram, and S. R. Coughlin, "Agonist recognition by proteinase-activated receptor 2 and thrombin receptor: importance of extracellular loop interactions for receptor function," The Journal of Biological Chemistry, vol. 271, no. 24, pp. 13943-13947, 1996.

[22] S. B. Elmariah, V. B. Reddy, and E. A. Lerner, "Cathepsin S signals via PAR2 and generates a novel tethered ligand receptor agonist," PLoS ONE, vol. 9, no. 6, Article ID e99702, 2014.

[23] R. Ramachandran, K. Mihara, H. Chung et al., "Neutrophil elastase acts as a biased agonist for proteinase-activated receptor-2 $\left(\mathrm{PAR}_{2}\right)$," The Journal of Biological Chemistry, vol. 286, no. 28, pp. 24638-24648, 2011.

[24] M.-K. Yau, L. Liu, and D. P. Fairlie, “Toward drugs for proteaseactivated receptor 2 (PAR2)," Journal of Medicinal Chemistry, vol. 56, no. 19, pp. 7477-7497, 2013. 
[25] B. Al-Ani, M. Saifeddine, and M. D. Hollenberg, "Detection of functional receptors for the proteinase-activated-receptor2-activating polypeptide, SLIGRL-NH2, in rat vascular and gastric smooth muscle," Canadian Journal of Physiology and Pharmacology, vol. 73, no. 8, pp. 1203-1207, 1995.

[26] M. D. Hollenberg, M. Saifeddine, and B. Al-Ani, "Proteinaseactivated receptor-2 in rat aorta: structural requirements for agonist activity of receptor-activating peptides," Molecular Pharmacology, vol. 49, no. 2, pp. 229-233, 1996.

[27] M. D. Hollenberg, M. Saifeddine, B. Al-Ani, and A. Kawabata, "Proteinase-activated receptors: structural requirements for activity, receptor cross-reactivity, and receptor selectivity of receptor-activating peptides," Canadian Journal of Physiology and Pharmacology, vol. 75, no. 7, pp. 832-841, 1997.

[28] J. J. McGuire, M. Saifeddine, C. R. Triggle, K. Sun, and M. D. Hollenberg, "2-Furoyl-LIGRLO-amide: a potent and selective proteinase-activated receptor 2 agonist," Journal of Pharmacology and Experimental Therapeutics, vol. 309, no. 3, pp. 1124-1131, 2004.

[29] G. D. Barry, J. Y. Suen, G. T. Le, A. Cotterell, R. C. Reid, and D. P. Fairlie, "Novel agonists and antagonists for human protease activated receptor 2," Journal of Medicinal Chemistry, vol. 53, no. 20, pp. 7428-7440, 2010.

[30] J. G. Seitzberg, A. E. Knapp, B. W. Lund et al., "Discovery of potent and selective small-molecule PAR-2 agonists," Journal of Medicinal Chemistry, vol. 51, no. 18, pp. 5490-5493, 2008.

[31] S. Boitano, J. Hoffman, D. V. Tillu et al., "Development and evaluation of small peptidomimetic ligands to protease-activated receptor-2 (PAR2) through the use of lipid tethering," PLoS ONE, vol. 9, no. 6, Article ID e99140, 2014.

[32] A. N. Flynn, D. V. Tillu, M. N. Asiedu et al., "The proteaseactivated receptor-2-specific agonists 2-aminothiazol-4-ylLIGRL-NH2and 6-aminonicotinyl-LIGRL- $\mathrm{NH}_{2}$ stimulate multiple signaling pathways to induce physiological responses in vitro and in vivo," The Journal of Biological Chemistry, vol. 286, no. 21, pp. 19076-19088, 2011.

[33] J. Y. Suen, G. D. Barry, R. J. Lohman et al., "Modulating human proteinase activated receptor 2 with a novel antagonist (GB88) and agonist (GB110)," British Journal of Pharmacology, vol. 165, no. 5, pp. 1413-1423, 2012.

[34] S. Boitano, J. Hoffman, A. N. Flynn et al., "The novel PAR2 ligand C391 blocks multiple PAR2 signalling pathways in vitro and in vivo," British Journal of Pharmacology, vol. 172, no. 18, pp. 4535-4545, 2015.

[35] L. M. Sevigny, P. Zhang, A. Bohm et al., "Interdicting proteaseactivated receptor-2-driven inflammation with cell-penetrating pepducins," Proceedings of the National Academy of Sciences of the United States of America, vol. 108, no. 20, pp. 8491-8496, 2011.

[36] A. Crilly, H. Palmer, M. B. Nickdel et al., "Immunomodulatory role of proteinase-activated receptor-2," Annals of the Rheumatic Diseases, vol. 71, no. 9, pp. 1559-1566, 2012.

[37] J. Hoffman, A. N. Flynn, D. V. Tillu et al., "Lanthanide labeling of a potent protease activated receptor-2 agonist for time-resolved fluorescence analysis," Bioconjugate Chemistry, vol. 23, no. 10, pp. 2098-2104, 2012.

[38] M. D. Hollenberg, B. Renaux, E. Hyun et al., "Derivatized 2-furoyl-LIGRLO-amide, a versatile and selective probe for proteinase-activated receptor 2: Binding and visualization," Journal of Pharmacology and Experimental Therapeutics, vol. 326, no. 2, pp. 453-462, 2008.
[39] E. B. Kelso, J. C. Lockhart, T. Hembrough et al., “Therapeutic promise of proteinase-activated receptor- 2 antagonism in joint inflammation," Journal of Pharmacology and Experimental Therapeutics, vol. 316, no. 3, pp. 1017-1024, 2006.

[40] R.-J. Lohman, A. J. Cotterell, J. Suen et al., "Antagonism of protease-activated receptor 2 protects against experimental colitis," Journal of Pharmacology and Experimental Therapeutics, vol. 340, no. 2, pp. 256-265, 2012.

[41] J. Y. Suen, A. Cotterell, R. J. Lohman et al., "Pathway-selective antagonism of proteinase activated receptor 2," British Journal of Pharmacology, vol. 171, no. 17, pp. 4112-4124, 2014.

[42] K. O'Callaghan, A. Kuliopulos, and L. Covic, “Turning receptors on and off with intracellular pepducins: new insights into Gprotein-coupled receptor drug development," The Journal of Biological Chemistry, vol. 287, no. 16, pp. 12787-12796, 2012.

[43] J. J. McGuire, M. D. Hollenberg, P. Andrade-Gordon, and C. R. Triggle, "Multiple mechanisms of vascular smooth muscle relaxation by the activation of proteinase-activated receptor 2 in mouse mesenteric arterioles," British Journal of Pharmacology, vol. 135, no. 1, pp. 155-169, 2002.

[44] J. J. McGuire, "Proteinase-activated Receptor 2 (PAR2): a challenging new target for treatment of vascular diseases," Current Pharmaceutical Design, vol. 10, no. 22, pp. 2769-2778, 2004.

[45] G. M. Tennant, R. M. Wadsworth, and S. Kennedy, "PAR-2 mediates increased inflammatory cell adhesion and neointima formation following vascular injury in the mouse," Atherosclerosis, vol. 198, no. 1, pp. 57-64, 2008.

[46] F. Roviezzo, M. Bucci, V. Brancaleone et al., "Proteinaseactivated receptor-2 mediates arterial vasodilation in diabetes," Arteriosclerosis, Thrombosis, and Vascular Biology, vol. 25, no. 11, pp. 2349-2354, 2005.

[47] T. Matsumoto, K. Ishida, K. Taguchi, T. Kobayashi, and K. Kamata, "Mechanisms underlying enhanced vasorelaxant response to protease-activated receptor 2 -activating peptide in type 2 diabetic Goto-Kakizaki rat mesenteric artery," Peptides, vol. 30, no. 9, pp. 1729-1734, 2009.

[48] Y. Li, K. Mihara, M. Saifeddine et al., "Perivascular adipose tissue-derived relaxing factors: release by peptide agonists via proteinase-activated receptor-2 (PAR2) and non-PAR2 mechanisms," British Journal of Pharmacology, vol. 164, no. 8, pp. 19902002, 2011.

[49] Z. J. Cheng, Y.-F. Jiang, H. Ding, D. Severson, and C. R. Triggle, "Vascular dysfunction in type 2 diabetic TallyHo mice: role for an increase in the contribution of $\mathrm{PGH} 2 / \mathrm{TxA} 2$ receptor activation and cytochrome p450 products," Canadian Journal of Physiology and Pharmacology, vol. 85, no. 3-4, pp. 404-412, 2007.

[50] Y. Park, J. Yang, H. Zhang, X. Chen, and C. Zhang, "Effect of PAR2 in regulating TNF- $\alpha$ and $\mathrm{NAD}(\mathrm{P}) \mathrm{H}$ oxidase in coronary arterioles in type 2 diabetic mice," Basic Research in Cardiology, vol. 106, no. 1, pp. 111-123, 2011.

[51] S. Kagota, E. Chia, and J. J. McGuire, "Preserved arterial vasodilatation via endothelial protease-activated receptor-2 in obese type 2 diabetic mice," British Journal of Pharmacology, vol. 164, no. 2, pp. 358-371, 2011.

[52] S. Kagota, K. Maruyama, H. Wakuda et al., "Disturbance of vasodilation via protease-activated receptor 2 in SHRSP.ZLepr $^{\text {fa }} /$ IzmDmcr rats with metabolic syndrome," Vascular Pharmacology, vol. 63, no. 1, pp. 46-54, 2014.

[53] L. Howitt, M. J. Morris, S. L. Sandow, and T. V. Murphy, "Effect of diet-induced obesity on $\mathrm{BK}(\mathrm{Ca})$ function in contraction 
and dilation of rat isolated middle cerebral artery," Vascular Pharmacology, vol. 61, no. 1, pp. 10-15, 2014.

[54] C. Wei, E. Geras-Raaka, B. Marcus-Samuels, Y. Oron, and M. C. Gershengorn, "Trypsin and thrombin accelerate aggregation of human endocrine pancreas precursor cells," Journal of Cellular Physiology, vol. 206, no. 2, pp. 322-328, 2006.

[55] E. Hyun, R. Ramachandran, N. Cenac et al., "Insulin modulates protease-activated receptor 2 signaling: implications for the innate immune response," Journal of Immunology, vol. 184, no. 5, pp. 2702-2709, 2010.

[56] P. Wang, Y. Jiang, Y. Wang, J. Y. Shyy, and K. A. DeFea, "Betaarrestin inhibits CAMKKbeta-dependent AMPK activation downstream of protease-activated-receptor-2," BMC Biochemistry, vol. 11, article 36, 2010.

[57] L. Badeanlou, C. Furlan-Freguia, G. Yang, W. Ruf, and F. Samad, "Tissue factor-protease-activated receptor 2 signaling promotes diet-induced obesity and adipose inflammation," Nature Medicine, vol. 17, no. 11, pp. 1490-1497, 2011.

[58] F. Borrelli, R. Capasso, B. Severino et al., "Inhibitory effects of bromelain, a cysteine protease derived from pineapple stem (Ananas comosus), on intestinal motility in mice," Neurogastroenterology and Motility, vol. 23, no. 8, p. 745-e331, 2011.

[59] A. Sumi, N. Yamanaka-Hanada, F. Bai, T. Makino, H. Mizukami, and T. Ono, "Roles of coagulation pathway and factor Xa in the progression of diabetic nephropathy in $\mathrm{db} / \mathrm{db}$ mice," Biological and Pharmaceutical Bulletin, vol. 34, no. 6, pp. 824-830, 2011.

[60] J. G. Rasmussen, S. E. Riis, O. Frøbert et al., "Activation of protease-activated receptor 2 induces VEGF independently of HIF-1," PLoS ONE, vol. 7, no. 9, Article ID e46087, 2012.

[61] L. Pilgaard, P. Lund, T. Fink, and V. Zachar, "Comparative analysis of highly defined proteases for the isolation of adipose tissue-derived stem cells," Regenerative Medicine, vol. 3, no. 5, pp. 705-715, 2008.

[62] P. B. Shetty, H. Tang, B. O. Tayo et al., "Variants in CXADR and F2RL1 are associated with blood pressure and obesity in African-Americans in regions identified through admixture mapping," Journal of Hypertension, vol. 30, no. 10, pp.1970-1976, 2012.

[63] J. Lim, A. Iyer, L. Liu et al., "Diet-induced obesity, adipose inflammation, and metabolic dysfunction correlating with PAR2 expression are attenuated by PAR2 antagonism," The FASEB Journal, vol. 27, no. 12, pp. 4757-4767, 2013.

[64] S. W. Görgens, K. Eckardt, M. Elsen, N. Tennagels, and J. Eckel, "Chitinase-3-like protein 1 protects skeletal muscle from TNF $\alpha$ induced inflammation and insulin resistance," Biochemical Journal, vol. 459, no. 3, pp. 479-488, 2014.

[65] N. Wronkowitz, S. W. Görgens, T. Romacho et al., "Soluble DPP4 induces inflammation and proliferation of human smooth muscle cells via protease-activated receptor 2," Biochimica et Biophysica Acta (BBA)-Molecular Basis of Disease, vol. 1842, no. 9, pp. 1613-1621, 2014.

[66] W. H. Yiu, D. W. L. Wong, L. Y. Y. Chan et al., "Tissue kallikrein mediates pro-inflammatory pathways and activation of protease-activated receptor-4 in proximal tubular epithelial cells," PLoS ONE, vol. 9, no. 2, Article ID e88894, 2014.

[67] J. Wang, S. Chakrabarty, Q. Bui, W. Ruf, and F. Samad, "Hematopoietic tissue factor-protease-activated receptor 2 signaling promotes hepatic inflammation and contributes to pathways of gluconeogenesis and steatosis in obese mice," The American Journal of Pathology, vol. 185, no. 2, pp. 524-535, 2015.

[68] S. Nystedt, V. Ramakrishnan, and J. Sundelin, "The proteinaseactivated receptor 2 is induced by inflammatory mediators in human endothelial cells. Comparison with the thrombin receptor," The Journal of Biological Chemistry, vol. 271, no. 25, pp. 14910-14915, 1996.

[69] M. N. Adams, C. N. Pagel, E. J. MacKie, and J. D. Hooper, "Evaluation of antibodies directed against human protease-activated receptor-2," Naunyn-Schmiedeberg's Archives of Pharmacology, vol. 385, no. 9, pp. 861-873, 2012.

[70] P. Zhao, M. Metcalf, and N. W. Bunnett, "Biased signaling of protease-activated receptors," Frontiers in Endocrinology, vol. 5, article 67, 2014.

[71] N. Sitaras, J. C. Rivera, B. Noueihed et al., "Retinal neurons curb inflammation and enhance revascularization in ischemic retinopathies via proteinase-activated receptor-2," American Journal of Pathology, vol. 185, no. 2, pp. 581-595, 2014.

[72] J. J. McGuire, B. N. Van Vliet, and S. J. Halfyard, "Blood pressures, heart rate and locomotor activity during salt loading and angiotensin II infusion in protease-activated receptor 2 (PAR2) knockout mice," BMC Physiology, vol. 8, article 20, 2008.

[73] J. J. McGuire, B. N. Van Vliet, J. Giménez, J. C. King, and S. J. Halfyard, "Persistence of PAR-2 vasodilation despite endothelial dysfunction in BPH/2 hypertensive mice," Pflugers Archiv, vol. 454, no. 4, pp. 535-543, 2007.

[74] E. Chia, S. Kagota, E. P. Wijekoon, and J. J. McGuire, "Protection of protease-activated receptor 2 mediated vasodilatation against angiotensin II-induced vascular dysfunction in mice," $B M C$ Pharmacology, vol. 11, article 10, 2011.

[75] B. Zhong and D. H. Wang, "Protease-activated receptor 2-mediated protection of myocardial ischemia-reperfusion injury: role of transient receptor potential vanilloid receptors," American Journal of Physiology. Regulatory, integrative and Comparative Physiology, vol. 297, no. 6, pp. R1681-R1690, 2009.

[76] F. Cattaruzza, N. Cenac, E. Barocelli et al., "Protective effect of proteinase-activated receptor 2 activation on motility impairment and tissue damage induced by intestinal ischemia/reperfusion in rodents," American Journal of Pathology, vol. 169, no. 1, pp. 177-188, 2006.

[77] A. F. Milia, M. B. Salis, T. Stacca et al., "Protease-activated receptor-2 stimulates angiogenesis and accelerates hemodynamic recovery in a mouse model of hindlimb ischemia," Circulation Research, vol. 91, no. 4, pp. 346-352, 2002.

[78] P. G. McLean, D. Aston, D. Sarkar, and A. Ahluwalia, "Proteaseactivated receptor-2 activation causes EDHF-like coronary vasodilation: selective preservation in ischemia/reperfusion injury: involvement of lipoxygenase products, VR1 receptors, and C-fibers," Circulation Research, vol. 90, no. 4, pp. 465-472, 2002.

[79] C. Napoli, F. de Nigris, C. Cicala et al., "Protease-activated receptor-2 activation improves efficiency of experimental ischemic preconditioning," American Journal of PhysiologyHeart and Circulatory Physiology, vol. 282, no. 6, pp. H2004H2010, 2002.

[80] K. Oikonomopoulou, K. K. Hansen, M. Saifeddine et al., "Kallikrein-mediated cell signalling: targeting proteinaseactivated receptors (PARs)," Biological Chemistry, vol. 387, no. 6, pp. 817-824, 2006.

[81] E. P. Feener, Q. Zhou, and W. Fickweiler, "Role of plasma kallikrein in diabetes and metabolism," Thrombosis and Haemostasis, vol. 110, no. 3, pp. 434-441, 2013.

[82] R. T. Abdallah, J.-S. Keum, M.-H. Lee et al., "Plasma kallikrein promotes epidermal growth factor receptor transactivation and signaling in vascular smooth muscle through direct activation 
of protease-activated receptors," The Journal of Biological Chemistry, vol. 285, no. 45, pp. 35206-35215, 2010.

[83] J. Robin, R. Kharbanda, P. Mclean, R. Campbell, and P. Vallance, "Protease-activated receptor 2-mediated vasodilatation in humans in vivo: role of nitric oxide and prostanoids," Circulation, vol. 107, no. 7, pp. 954-959, 2003.

[84] I. J. Gudmundsdóttir, I. L. Megson, J. S. Kell et al., "Direct vascular effects of protease-activated receptor type 1 agonism in vivo in humans," Circulation, vol. 114, no. 15, pp. 1625-1632, 2006.

[85] A. N. Flynn, J. Hoffman, D. V. Tillu et al., "Development of highly potent protease-activated receptor 2 agonists via synthetic lipid tethering," The FASEB Journal, vol. 27, no. 4, pp. 1498-1510, 2013.

[86] D. V. Tillu, S. N. Hassler, C. C. Burgos-Vega et al., "Proteaseactivated receptor 2 activation is sufficient to induce the transition to a chronic pain state," PAIN, vol. 156, no. 5, pp. 859-867, 2015.

[87] S. G. Shimada, K. A. Shimada, and J. G. Collins, "Scratching behavior in mice induced by the proteinase-activated receptor-2 agonist, SLIGRL-NH2," European Journal of Pharmacology, vol. 530, no. 3, pp. 281-283, 2006.

[88] J. Buddenkotte, C. Stroh, I. H. Engels et al., "Agonists of proteinase-activated receptor- 2 stimulate upregulation of intercellular cell adhesion molecule-1 in primary human keratinocytes via activation of NF-kappa B," Journal of Investigative Dermatology, vol. 124, no. 1, pp. 38-45, 2005.

[89] N. Zhang and D. A. Lawrence, "Tissue factor and obesity, a twoway street," Nature Medicine, vol. 17, no. 11, pp. 1343-1344, 2011. 

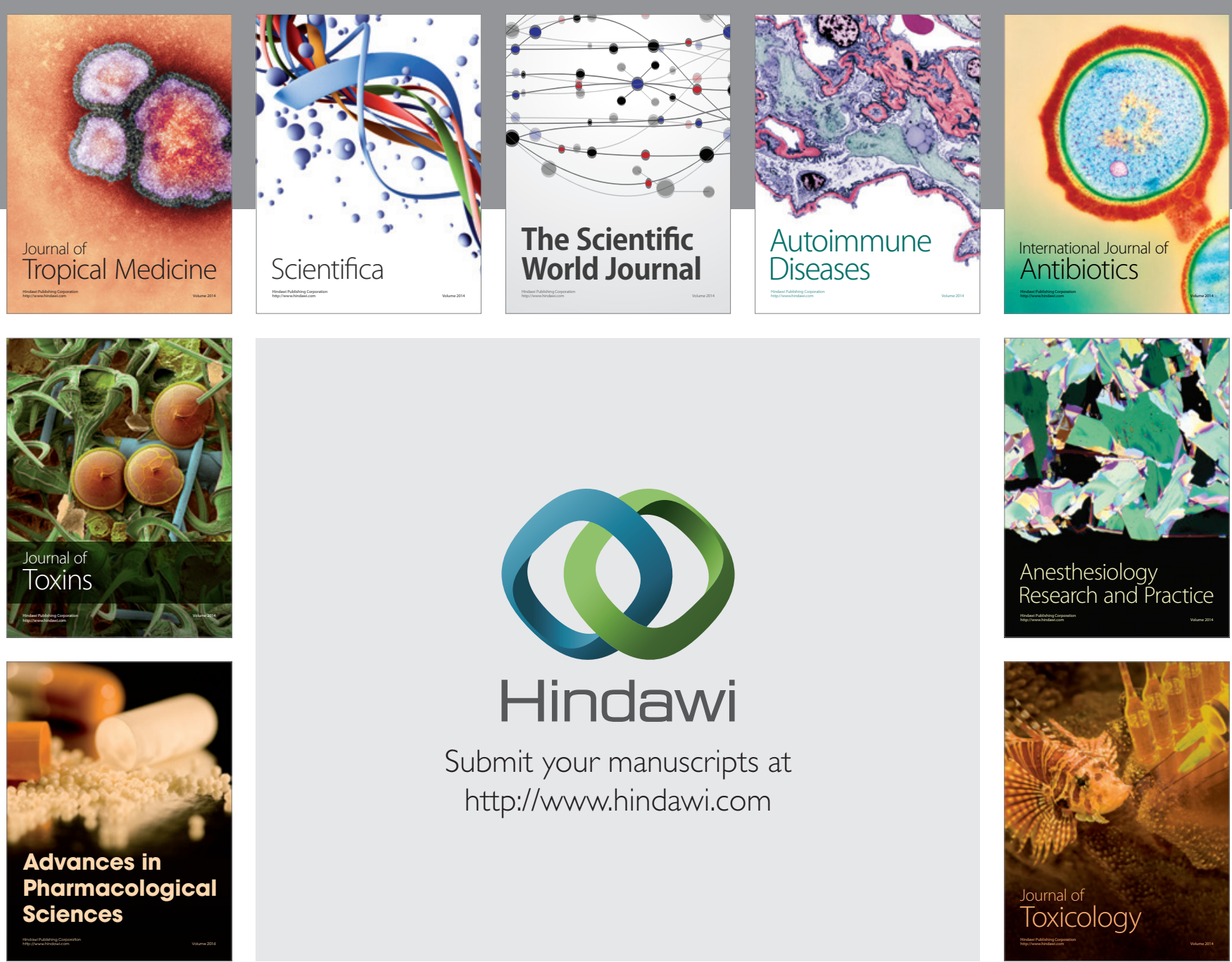

\section{Hindawi}

Submit your manuscripts at

http://www.hindawi.com
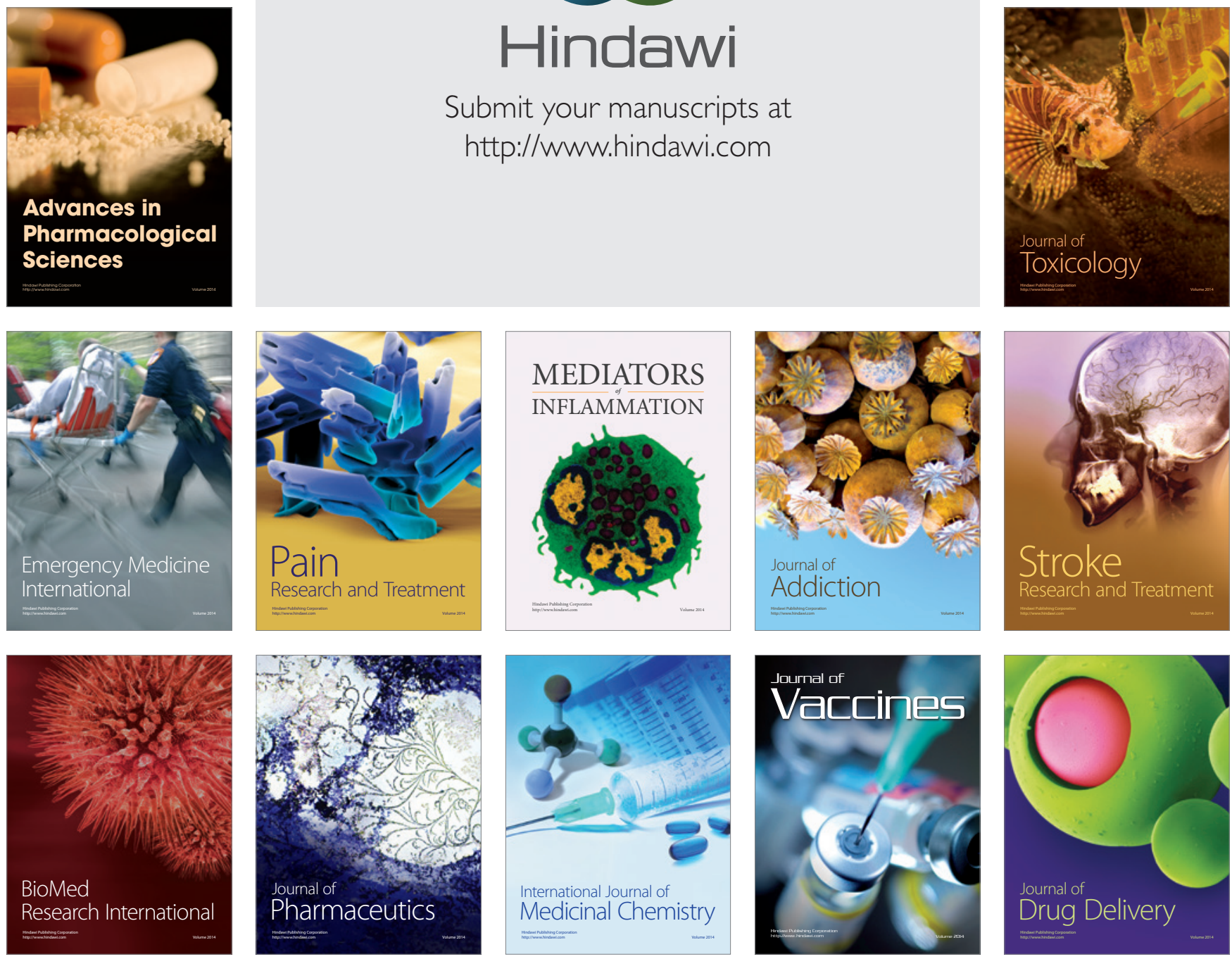